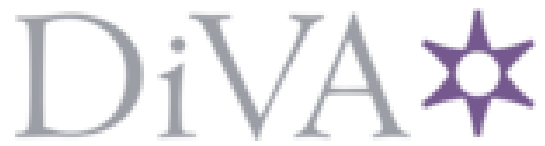

http://www.diva-portal.org

This is the published version of a paper published in De Ethica.

Citation for the original published paper (version of record):

Svensson, F. (2017)

A Subjectivist Account of Life's Meaning

De Ethica, 4(3): 45-66

https://doi.org/10.3384/de-ethica.2001-8819.174345

Access to the published version may require subscription.

N.B. When citing this work, cite the original published paper.

This work is licensed under a Creative Commons Attribution-NonCommercial 4.0 International License.

Permanent link to this version:

http://urn.kb.se/resolve?urn=urn:nbn:se:umu:diva-140130 


\title{
A Subjectivist Account of Life's Meaning
}

\author{
Frans Svensson
}

In this paper, I propose and defend a particular desire-based theory of what makes a person's life meaningful. Desire-based theories avoid the problems facing other theories of meaning in life: in contrast to objectivist theories (both consequentialist and non-consequentialist ones), they succeed in providing a necessary link between what makes a person's life meaningful and the person's own set of attitudes or concerns; in contrast to hybrid theories (or subjectivist theories with a value requirement), they avoid the elitism or exclusivism inherent in the former; and in contrast to mental-state theories, they avoid the problem of not taking the state of the world properly into account when determining whether someone's life is meaningful. However, meaningfulness does not plausibly depend on the satisfaction of just any desires-perhaps especially not on the satisfaction of desires that we experience as alien to ourselves. I therefore suggest that the meaning in your life depends on the extent to which your categorical desires (i.e. those desires that are partly constitutive of your practical identity) are satisfied or fulfilled. In the final section of the paper, I respond to at least four possible objections to this view.

\section{Introduction}

My aim in this paper is to offer a defense of a certain subjectivist account or theory of what makes a human person's life meaningful. According to the view I will defend, your life is meaningful to the extent that your categorical desires-i.e. those desires that are partly constitutive of your practical identity, or of who you are as a practical agent-are fulfilled or satisfied. ${ }^{1}$ For short I will henceforth refer to this account as CDF.

\footnotetext{
1 The notion of categorical desires here is due to Bernard Williams, 'Persons, Character and Morality', in Moral Luck: Philosophical Papers 1973-1980 (Cambridge: Cambridge University Press, 1981); see also his 'The Makropulos Case; Reflections on the Tedium of Immortality', in Problems of the Self: Philosophical Papers 1956-1972 (Cambridge: Cambridge University Press, 1973). According to Williams, categorical desires are desires that we identify with; desires that a person 'finds his life bound up with ... and that ... propel him forward, and thus ... give him a reason for living his life' ('Persons, Character and Morality', p. 14). This is what I have in mind when saying that someone's categorical desires are (at least partly) constitutive of that person's practical identity. (Compare
} 
I begin below with some relevant background (section 1). The subsequent three sections (2-4) are spent developing my defense of CDF in response to the problems afflicting other accounts or theories. In section 5, I respond to four possible objections against CDF. The paper ends with a brief summary of my discussion.

\section{Stage Setting}

In this section I will begin by making at least five remarks about what shall be meant with 'a meaningful life' and other cognate phrases or expressions in what follows (1.1). Then I will clarify what I take the philosophical discussion regarding what makes a person's life meaningful to be more specifically about (1.2). Lastly, I will introduce a distinction between two general types of theory about what makes for a meaningful life: objectivism and subjectivism (1.3).

\subsection{Five Conceptual Remarks}

(i) I will be concerned with meaning in life in the sense of something that is essentially exemplified by a human person. I will thus not be interested in the meaning of human life as a whole-with, e.g., the end or purpose for which human life exists or has been created by God.2 Nor will I be concerned with the meaning that perhaps can be exemplified in the lives of non-human animals and plants; with why other species exist; or, indeed, with the meaning of life itself, in all of its different forms.

(ii) By 'a meaningful life' I shall furthermore intend a life that, in the words of Susan Wolf:

has within it the basis for an affirmative answer to the needs or longings that are characteristically described as needs for meaning. I have in mind, for example, the sort of questions people ask on their deathbeds, or simply in contemplation of their eventual deaths, about whether their lives have been (or are) worth living, whether they have had any point, and the sort of questions one asks when considering suicide and wondering whether one has any reason to go on. ${ }^{3}$

One important question that needs to be addressed in connection with the above, however, is for/to whom or what, or from which perspective, a life must have a point or be

Christine M. Korsgaard, The Sources of Normativity, (Cambridge: Cambridge University Press, 1996), p. 101: 'The conception of one's identity in question here is not a theoretical one, a view about what as a matter of inescapable scientific fact you are. It is better understood as a description under which ... you find your life to be worth living and your actions to be worth undertaking. So I will call this a conception of your practical identity'.)

2 The question of why human life exists is (nowadays, at least) perhaps usually thought to belong to the purview of religion. For a discussion of what alternatives there may be for secular thinkers to find a satisfying answer to that question, see Thomas Nagel's remarkable paper 'Secular Philosophy and the Religious Temperament', in Secular Philosophy and the Religious Temperament: Essays 2002-2008 (Oxford: Oxford University Press, 2010), chapter 1.

3 Wolf, 'Happiness and Meaning: Two Aspects of the Good Life', in The Variety of Values: Essays on Morality, Meaning, and Love (Oxford: Oxford University Press, 2015), p. 109. 
worth living in order to qualify as a meaningful life. ${ }^{4}$ This question is sometimes (though not always, of course) sidestepped in the recent literature on life's meaning. ${ }^{5}$ It really shouldn't be, though, since our answer to it will surely matter with respect to which account of what makes for a meaningful life that will seem most promising to us. Here my concern will be with a meaningful life in the sense of a life that is meaningful to the person whose life it is; or, if you will, in the sense of a life that matters, makes a difference, or is worthwhile from the person's own perspective. Our lives can certainly be meaningful (important, matter, make a difference) in other ways or senses as well, however. Jill's life, e.g., may be tremendously important for her partner; George may mean a lot to the English department at the local university; John may have made a difference to the village where he lived his life; and Miriam's life may perhaps have made an important difference from a cosmic perspective, i.e. 'when ... viewed from an impartial standpoint, all things considered-when literally all things are considered' ${ }^{6}$ But it seems an entirely open question whether meaning something in one or more of the ways just mentioned, is important, or contributes to making one's life meaningful, to oneself. And it is, again, a meaningful life in the latter sense that I will be interested in here. This is, I believe, also the sense of a meaningful life that most of us actually have in mind when thinking about whether our lives are meaningful or not.7

(iii) Thirdly, when using expressions such as 'a meaningful life', 'meaning in life', etc., I shall be intending a final value, i.e. something that is valuable or worth having for its own sake. ${ }^{8}$ I shall furthermore be intending a value that human persons can exemplify to a higher or lower degree in their lives.

(iv) Fourthly, and in the light of what was said in (ii) above, perhaps unsurprisingly, I will assume that meaning in life is a prudential, as opposed to e.g. a moral or an aesthetic, value. I will thus assume that if one's life exemplifies meaning, then one's life is, in at least one respect, going well for one.

Two things may be worth noticing in relation to this. Firstly, that meaning in life is prudentially valuable in no way excludes the possibility that moral uprightness and

\footnotetext{
4 No sense, it seems to me, can be made of the notion that some lives just are meaningful, full stop. As e.g. Guy Kahane, 'Our Cosmic Insignificance', Nous 48:4 (2014), pp. 745-772, points out (at p. 750): 'significance [which, I take it, is a synonym to meaning in this context] is relative to a point of view, it can vary in this way even as value stays fixed'.

5 E.g. Berit Brogaard and Barry Smith, 'On Luck, Responsibility and the Meaning of Life', Philosophical Papers 34:3 (2005), pp. 443-458; Antti Kauppinen, 'Meaningfulness and Time', Philosophy and Phenomenological Research 84:2 (2012), pp. 345-377; Arjan Markus, 'Assessing Views of Life: A Subjective Affair?', Religious Studies 39:2 (2003), pp. 125-143; and Erik J. Wielenberg, Value and Virtue in a Godless Universe (Cambridge: Cambridge University Press, 2005), chapter 2, all touch upon this issue in various ways.

6 Kahane, 'Our Cosmic Insignifcance', p. 750 (emphasis in original).

7 This is, I would suggest, to at least some extent confirmed by the vast amount of self-help or popular psychology books, webpages and TV-shows, offering advice on what we should do to make our lives more meaningful to ourselves.

8 This does not, of course, exclude the possibility that living a meaningful life might also be instrumentally valuable in various ways. (In an important paper, which I do not unfortunately have the space to engage with here, Chris Woodard suggests that meaning in life may in fact only be instrumentally valuable; see Woodard, 'What Good Is Meaning in Life?', De Ethica, this issue.)
} 
aesthetic activity may belong in the class of things that contribute to making people's lives meaningful. Rather, if moral uprightness and aesthetic activity do belong in that class of things, then besides making our lives morally and aesthetically valuable, they also contribute to making our lives prudentially valuable (in at least one respect). Secondly, that meaning in life is prudentially valuable does not exclude the possibility that there may be other prudential values as well. One such example would plausibly be happiness. At least in its modern sense of (roughly) experiencing feelings of pleasure or contentment, happiness seems to lack the dimension of depth that is characteristic of meaning in life (it is quite possible to, e.g., feel happy for no particular reason, or about things such as eating an ice cream, having a cold beer on a warm summer afternoon, etc., neither of which would (for most of us, at least) be important enough to confer meaning on our lives.). But happiness is plausibly a prudential value, something that makes one's life go well for one in at least one respect. ${ }^{9}$

(v) In the literature on life's meaning, it is commonly assumed that we can distinguish a class of paradigmatic examples of meaningful lives, including, e.g., the lives of Albert Einstein, Mother Teresa, Fyodor Dostoyevsky, Mahatma Gandhi, Pablo Picasso, and Nelson Mandela. The lives of these persons, as one author puts it, 'come to mind as unquestionably meaningful (if any are)'. ${ }^{10}$ And because of this, it should be possible for us to use these lives as test cases for different accounts or theories of what makes a person's life meaningful.

However, while attending to examples such Picasso, Einstein, and Mother Teresa presumably can be helpful when inquiring into what makes for a meaningful life, we should make sure that we attend to them with some care. For one thing, they are all lives of exceptional accomplishment. And even though great aesthetic, intellectual, or moral accomplishment is not, of course, incompatible with living a meaningful life, it is certainly not essential for doing so; on the contrary, most lives that qualify as meaningful (if any do) are not lives of such accomplishment. It is important, I submit, that we already from the beginning take seriously not only the lofty goals of the true, the good, and the beautiful, but also, and perhaps even in particular, the great variety of (in comparison) mundane things that we ordinarily seem to take it for granted do or can contribute to making people's lives meaningful, including, e.g., spending time with one's family, bird watching, cooking, collecting wrist watches, moral decency, singing, travelling, working as a teacher, and gliding. Secondly, the status of lives such as Picasso's, Einstein's, and Mother Teresa's as paradigmatic or unquestionable examples of meaningful lives is not, as it were, set in stone. Suppose, for example, that biographers were to recover unassailable

\footnotetext{
9 There are, of course, also other and much more demanding notions of happiness (even today!); see e.g. Philippa Foot's excellent discussion of what she characterizes as deep happiness in her Natural Goodness (Oxford: Oxford University Press, 2001), chapter 6. On the contrast between modern and classical eudaimonistic conceptions of happiness, see, for example, Julia Annas, Intelligent Virtue (Oxford: Oxford University Press, 2011), chapters 8-9; Richard Kraut, 'Two Conceptions of Happiness', The Philosophical Review 88:2 (1979), pp. 167-197; and Daniel C. Russell, Happiness for Humans (Oxford: Oxford University Press, 2012). Comparing these more demanding notions of happiness with meaning in life would be quite interesting, but it will have to wait for another occasion.

10 Wolf, 'Happiness and Meaning: Two Aspects of the Good Life', p. 109.
} 
evidence that Mother Teresa was not, in fact, motivated by compassion when caring for her patients, but only by a deeply held fear for the wrath of God, which tormented her inside and made it impossible for her to ever find any satisfaction or personal fulfillment in what she did. Many of us would then start to waiver in our conviction that Mother Teresa's life was really a meaningful one; at least some argument would now be required to show that it was. Or suppose that certain documents were found showing that Einstein stole the discoveries that he is known for from a friend or colleague who passed away before she was able to make them public. Einstein's life would then surely not come to mind as unquestionably meaningful anymore.

\title{
1.2 What Makes a Person's Life Meaningful?
}

When asking the question of 'What makes a person's life meaningful?' it seems we could be interested in simply coming up with a list of things that do or can give meaning to people's lives. Alternatively, however, we could be interested in finding a more basic and systematic answer to the question: an answer consisting of an account of the feature or features that all of the things that do or can give meaning to people's lives have in common and in virtue of which our lives do or could acquire meaning from them. It is answers of the second kind that will be of interest here. If we could indeed find an account of the feature(s) that makes people's lives meaningful (if they are), then that should be quite interesting in its own right. But having such an account at our disposal could, it seems, also be useful: in cases of uncertainty, e.g., it should (at least in principle) enable us to determine whether (and to what extent) someone's life really does exemplify meaning or not.

\subsection{Two Types of Account: Subjectivism and Objectivism}

It will facilitate the discussion below to distinguish between two general types of account or theory of what makes a person's life meaningful: subjectivism and objectivism. I will here appropriate Wayne Sumner's way of distinguishing between subjectivist and objectivist theories in the case of welfare. Thus:

\begin{abstract}
Subjective theories make [meaning in life] logically dependent on our attitudes of favour and disfavor. Objective theories deny this dependency. On an objective theory, therefore, something can be (directly and immediately) [meaningful] for me, though I do not regard it favourably, and my life can [be meaningful] despite my failing to have any positive attitude toward it. ${ }^{11}$
\end{abstract}

On this way of drawing the distinction, objectivist theories deny that meaning in life is even partly dependent on one's own attitudes or concerns. It is with this type of theory that I shall begin. I will argue that objectivist theories as a group can be set aside for one

11 L. Wayne Sumner, Welfare, Happiness, and Ethics (Oxford: Oxford University Press, 1996), p. 38. Since Sumner's concern in this passage is with welfare rather than life's meaning, I have changed 'well-being', 'good for me', and 'my life ... going well', to meaning in life and (in two places) meaningful. 
and the same reason, namely, for failing to make sense of how or why meaningful lives are meaningful to the persons whose lives they are. ${ }^{12}$

\section{Objectivist Theories}

In this section I will begin by introducing a general problem that I believe afflicts all objectivist theories of what makes a person's life meaningful (2.1), and then go on to illustrate how the problem arises in the case of at least three influential examples of objectivist theories in the literature (2.2). ${ }^{13}$ After that I will consider a possible response to my objection against objectivist theories (2.3). That response, however, turns out to involve the rejection of objectivism in favour of a certain kind of subjectivist theory. I will end the section with a short addendum concerning the possibility that proponents of objectivist and subjectivist theories are perhaps best understood as being concerned with different concepts of meaning in life (2.4).

\subsection{A General Problem for Objectivist Theories}

The problem for objectivist theories that I will focus on here is basically the same as the problem that is often raised in relation to objectivist theories of wellbeing. This should not be especially surprising. In 1.1, remark (ii), I made it clear that I will be interested in what makes a life meaningful (matter, important, etc.) to the person whose life it is, and (remark (iv)) that meaning in life is therefore plausibly a prudential value. In the light of this, denying that meaning in life is even partly dependent on one's attitudes or concerns does indeed become problematic. Because by denying that the meaningfulness in a person's life depends at least in part on what that person likes, enjoys, cares about, or desires, it seems impossible for objectivist theories to explain why a meaningful life is one that matters, is important, or makes a difference to the person him- or herself, and thereby also why exemplifying meaning in one's life is something that is essentially good for one.

\subsection{Illustrations}

To illustrate how this problem arises for the objectivist type of theory, let us look at a few examples of objectivist theories that have been proposed recently.

\subsubsection{Consequentialism}

We might begin with the Good Cause Account (GCA), defended in an important paper by Aaron Smuts. ${ }^{14}$ GCA is a consequentialist theory, according to which a person's 'life is

12 My critique of objectivist theories of meaning in life is thus basically the same as Sumner's critique of objectivist theories of welfare; see Sumner, Welfare, Happiness, and Ethics, pp. $42-44$ and chapter 3.

${ }^{13}$ As we shall see, in the case of one of these theories viz. that of Erik J. Wielenberg, Value and Virtue in a Godless Universe (Cambridge: Cambridge University Press, 2005), chapter 2, it is not entirely clear whether it in the end constitutes an objectivist theory or not.

14 'The Good Cause Account of the Meaning of Life', The Southern Journal of Philosophy 51:4 (2013), pp. 536-562. 
meaningful to the extent that it promotes the good'. ${ }^{15}$ This is, it seems, a clear example of an objectivist theory. A person's life is meaningful, on GCA, insofar as it is the cause of objective value; there is no additional requirement that the person must also have one or another positive attitude (or, for that matter, lack any negative attitude) towards her life and the good that she is causing. The person's life would be meaningful even if she herself hates it or is entirely indifferent towards it. GCA would thus imply that, e.g., Sisyphus' life was meaningful, if we just add to the original version of the myth that his stone-rolling kept scaring off vultures that would otherwise cause much harm to the inhabitants of the village on the other side of the mountain. ${ }^{16}$ It would not matter if Sisyphus at all cares about helping the villagers, or if he is aware of helping them. In fact, it seems a person's life could be meaningful, according to GCA, even if the person is unable to exhibit any attitudes at all. Suppose, e.g., that someone spends his entire life in a comatose condition, in which he does not desire or feel anything. As it happens, however, he has an expression on his face that (for some reason) causes everyone who catches a glimpse of it to experience complete contentment and harmony inside. Assuming that experiencing complete contentment and harmony inside is objectively valuable, and that at least one person does catch a glimpse of the expression on the comatose individual's face, then that should be enough for making the comatose individual's life to at least some extent meaningful.

Now, both the existence of the comatose individual and the life of Sisyphus, in the revised version of the myth, are indeed meaningful, or make a difference, to others. And making a difference to others can plausibly contribute to making a life meaningful also to oneself; for most of us, it presumably does. But GCA fails to establish a necessary link between the attitudes or concerns of the person whose life it is and his or her making a difference to others. And in cases where such a link is missing, as it is in the two cases above, nothing is present to explain why the difference that one is making to others would make a difference to oneself.

\subsubsection{Non-Consequentialism}

In the literature, there are also examples of objectivist theories of a non-consequentialist stripe. According to Thaddeus Metz's fundamentality theory, e.g., one's life is meaningful (roughly) to the extent that it involves orienting one's 'rationality towards fundamental

15 Smuts, 'The Good Cause Account of the Meaning of Life', p. 535. Consequentialist accounts of meaning in life are proposed also in, e.g., Robert Audi, 'Intrinsic Value and the Meaning of Life', Philosophical Papers 34:3 (2005), pp. 331-355; Ben Bramble, 'Consequentialism about Meaning in Life', Utilitas 27:4 (2015), pp. 445-459; Irving Singer, Meaning of Life, Vol. 1: The Creation of Value (Baltimore: John Hopkins University Press, 1996); and Mark Wells, 'Meaning in Consequences', Journal of Philosophy of Life 5:3 (2015), pp. 169-179. One advantage of GCA, it seems to me, in comparison to the account proposed in, e.g., Bramble, 'Consequentialism about Meaning in Life', is that GCA is (at least potentially) less demanding. In contrast to Bramble's account, GCA does not require that in order for one's life to count as meaningful, it must make the world a better place than it would have been had one not existed at all. GCA may instead be read as saying simply that one's life is meaningful to the extent that it causes good, irrespective of whether even more good would have been produced by someone else if one had not existed.

16 The example is due to Susan Wolf, Meaning in Life and Why It Matters (Princeton: Princeton University Press, 2010), p. 21; cf. Smuts, 'The Good Cause Account of the Meaning of Life', p. 551. 
conditions of human existence' ${ }^{17}$ Another example might be the Aristotelian-inspired theory proposed by Erik J. Wielenberg, according to which a person's life is meaningful insofar as she is engaged in intrinsically valuable activities, including e.g. 'falling in love, engaging in intellectually stimulating activity, being creative in various ways, experiencing pleasure of various kinds, and teaching'.18 Since both of these theories involve essential references to activity of some form or other, they avoid the implication that the life of a permanently comatose individual could exemplify meaning. And on the seemingly plausible assumption that Sisyphus, even in the revised version of the myth, is not engaged in either intrinsically valuable activity (though he is, of course, engaged in instrumentally valuable activity) or in orienting his rationality towards fundamental aspects of the human condition, both Wielenberg's and Metz's theories avoid the second example above as well. However, insofar as being engaged in intrinsically valuable activity or orienting one's rationality towards fundamental aspects of human existence can be done independently of whether one has any kind of positive attitude towards it, it is nevertheless clear that these theories too are unable to explain why living a meaningful life is a matter of living a life that necessarily matters or is important to oneself.

\subsection{A Possible Response?}

Maybe, though, Metz, Wielenberg, and proponents of other similar non-consequentialist theories could respond to my criticism by arguing that the kinds of activities that they claim are essential to meaning in life are such that they in fact necessarily involve one or another positive attitude. At least with respect to Wielenberg's theory, this may indeed seem a fairly natural response. The theory is explicitly inspired by Aristotle, and Aristotle, after all, made it a condition on excellent or virtuous activity - the kind of activity that, I take it, he considered to be intrinsically valuable - that one enjoys it. ${ }^{19}$ Furthermore, at least some of the examples on Wielenberg's list of intrinsically valuable activities do involve references to attitudes (in particular 'experiencing pleasure of various kinds'). Whether the response is open in relation also to Metz's fundamentality theory is perhaps less clear (it is hard to see why orienting one's rationality towards fundamental aspects of human existence would necessarily have to involve any positive attitude on one's part), but I do not see any reason for why the theory could not be just slightly amended to incorporate it. ${ }^{20}$

17 Thaddeus Metz, Meaning in Life: An Analytic Study (Oxford: Oxford University Press, 2013), p. 222. Metz's full statement of his fundamentality theory is quite a mouthful. It reads: 'A human person's life is more meaningful, the more that she, without violating certain moral constraints against degrading sacrifice, employs her reason and in ways that either positively orient rationality toward fundamental conditions of human existence, or negatively orient it towards what threatens them; in addition, the meaning in a human person's life is reduced, the more it is negatively oriented towards fundamental conditions of human existence' (p. 233).

18 Wielenberg, Value and Virtue in a Godless Universe, p. 34. A similar view is developed at greater length as a theory of welfare in Stephen Darwall, Welfare as Rational Care (Princeton: Princeton University Press, 2002), chapter 4.

19 See, e.g., Aristotle, Nicomachean Ethics (Cambridge: Cambridge University Press, 2000; translated and edited by Roger Crisp), II.3.

20 If I understand him correctly, Metz himself would not be disposed to amend his theory in such a way. He writes, e.g., that he takes there to be 'reason to doubt that any propositional attitude, 
Now if Metz and/or Wielenberg were to respond in the way suggested just above, then that would enable them to avoid the general difficulty for objectivist theories that I have been pressing. It would do so, however, only as a consequence of giving up on objectivism (as that is being conceived here) in favour of a certain kind of subjectivism, since it would no longer be the case that meaning in life, on their views, is entirely independent of our attitudes or concerns.

\subsection{Addendum: Might Objectivists and Subjectivists Be Talking Past Each Other?}

One worry that perhaps could be raised here is whether proponents of objectivist theories should not be understood as being concerned with a different notion or concept of meaning in life than the one that I indicated in section 1, and which I think at least comes close to being the one that most subjectivists are interested in. In particular, should we perhaps think of objectivists as being concerned with what makes a person's life meaningful to others, or, say, from the perspective of the universe as a whole, whereas I, and perhaps other subjectivists, are concerned with what makes a person's life meaningful to oneself?

At the current stage of the philosophical debate regarding meaning in life, however, I think it makes good sense to treat objectivist and subjectivist theories as being concerned with the same topic. There are at least two reasons for this. Firstly, most participants in the discussion so far have indeed treated objectivist and subjectivist theories as competing theories of one and the same thing. And, secondly, treating them in this way should hopefully help us become clearer about the strengths and weaknesses of the respective theories in relation to what, upon closer examination, may turn out to be different concepts of meaning in life.

\section{Subjectivism I: Subjectivist Theories with a Value Requirement}

If Metz and Wielenberg were to endorse the response suggested in 2.3 to the general problem for objectivist theories, then their theories would count not as objectivist but rather as hybrid ones-or, as they (again drawing on Sumner) could also be labelled, subjectivist theories with a value requirement. ${ }^{21}$ I.e. they would then constitute examples of theories according to which a person's life is meaningful not only in virtue of meeting a certain condition of objective value, but also in virtue of meeting one or another subjective attitudinal condition. Now, the single most influential theory of meaning in life in contemporary philosophy in fact constitutes a theory of precisely this kind. The theory I have in mind is Susan Wolf's fitting fulfillment view, which, in its by now rather famous slogan version, says that 'meaning arises when subjective attraction meets objective attractiveness'.22 The details of Wolf's view, as it is presented in this slogan version, could

positive or negative, is necessarily constitutive of one's life being somewhat more meaningful' (Meaning in Life:, p. 184; emphasis in original). He adds, however, that 'certain attitudes ... might [nevertheless] be necessary for one's life to count as meaningful on balance' (Ibid.).

21 See Sumner, Welfare, Happiness, and Ethics, p. $163 \mathrm{f}$.

22 Wolf, 'Happiness and Meaning: Two Aspects of the Good Life', p. 112. R. W. Hepburn, 'Questions about the Meaning of Life', Religious Studies 1:2 (1966), pp. 125-140, seems to be an early 
be filled out in different ways. Wolf herself, however, argues that a meaningful life should more specifically be conceived as one of finding fulfillment in activities of objective worth, or perhaps as one of loving engagement in projects that are, objectively speaking, worthy of being loved.

By constituting a kind of subjectivist theory, Wolf's does indeed contain a necessary link between what makes a person's life meaningful and the person's own 'set of attitudes or concerns' 23 . It is thereby able to make sense of meaning in life as something that matters essentially to the person whose life it is. So far so good! However, her theory (as well as other theories like it) is subject to another important problem, namely that it is implausibly elitist or, if you will, exclusivist.

To see why this is the case, consider two of the examples offered by Wolf (the first one) and Wielenberg (the second) of activities that perhaps may be relaxing and/or enjoyable, but which are, allegedly, in themselves worthless, and therefore, on the hybrid view, cannot contribute to making anyone's life meaningful - not even if one were to find them deeply fulfilling: solving crossword puzzles and playing video games. ${ }^{24}$ One obviously quite important concern in relation to these two examples is how, if at all, we can know that solving crossword puzzles and playing video games are intrinsically worthless or unimportant (and similarly we may of course ask how we can know that certain other activities are intrinsically valuable or of objective worth). ${ }^{25}$ I shall set this concern to one side, however, and instead simply grant, for the sake of argument, that the relevant activities do actually lack value in themselves, and that there is some way in which we can, at least in principle, gain knowledge about that. Even if these things are granted, however, it seems clear that someone could - and I suspect some people in fact do-in part live for playing video games and/or solving crossword puzzles; that these

proponent of this kind of view. Hybrid views are (if I understand them correctly) endorsed also in, e.g., Todd May, A Significant Life: Meaning in a Silent Universe (Chicago: University of Chicago Press, 2015), and Owen Flanagan, Self-Expressions: Mind, Morals, and the Meaning of Life (Oxford: Oxford University Press, 1996). Kauppinen, 'Meaningfulness and Time', develops a view that I believe is, in the end, objectivist, but which is explicitly influenced by Wolf's work in important respects. For a defense of Wolf's view against some recent objections, see Daan Evers and G. E. van Smeden, 'Meaning in Life: In Defense of the Hybrid View', The Southern Journal of Philosophy 54:3 (2016), pp. 355-371.

${ }^{23}$ Sumner, Welfare, Happiness, and Ethics, p. 81.

${ }^{24}$ See Wolf, Meaning in Life and Why It Matters, p. 16, and Wielenberg, Value and Virtue in a Godless Universe, p. 34f.

${ }^{25}$ Wolf certainly acknowledges this problem, but she does not really have anything to offer in response to it. Wielenberg, though, recommends that we use G. E. Moore's (in)famous isolation test: 'To see if an activity is intrinsically good, consider whether you would find it worthwhile even if it had absolutely no consequences. If it seems to you that it would be worthwhile, then you have a good candidate for an intrinsically good activity on your hands' (Wielenberg, Value and Virtue in a Godless Universe, p. 35; emphasis in original). But there are a number of problems associated with that procedure. For example, we may wonder whether our upbringing, cultural and social context, physical and psychic health, etc., will not play a rather large role in determining the judgments we make when considering things in the way the isolation test involves. Furthermore, if there is anything to holism about value, it seems the value of things might depend on their relation to other things, something which cannot, it seems, be taken into consideration when considering each thing in isolation from everything else. 
activities could be (and perhaps are) part of what makes the world go round for some people; that they matter deeply to them; that they are part of what gives a point or purpose to their lives. Now, maybe these activities do not plausibly confer any meaning on your, my, or on his or her, life. But why would we want to exclude the possibility that they may very well confer meaning on some other people's lives? How could that amount to anything but an unacceptably elitist or exclusivist stance on our part?

Perhaps it will be objected to what I have just said that it is surely conceivable that for many people, the importance that they attach to different activities in their lives - whether it be to playing video games, attending performances of Wagner's Ring, or teaching in the English department-is, as it were, conditional on the relevant activities being objectively valuable. If these people came to realize that the activities to which they are deeply attached were not, in fact, objectively valuable, then they would thus immediately agree that their attachments to those activities had been wasted-that devoting themselves to the relevant activities, whatever they used to believe about it, never did confer any meaning upon their lives. With respect to such persons, is it not $I$ who could be accused of being elitist? Given what I said above, must I not say that they would be wrong to think that their lives lacked meaning even before they realized that the objects of their attachments were not objectively valuable?

No, I neither must nor want to say that at all. I fully agree, in fact, that it is conceivable (indeed, I think it is true) that there are people whose attachments in life are conditional on the objects of those attachments being objectively valuable. But that does not commit me to a hybrid-or, for that matter, an objectivist-view of what makes a person's life meaningful. It would, e.g., be perfectly open to me to argue (as indeed I will argue in section 4 below!) that the crucial feature with respect to the kind of persons that the objector is referring to is that their desires for the activities they are attached to are conditional upon those activities being objectively valuable. And thus if the activities are not objectively valuable, then being engaged in them does not satisfy or fulfill the relevant persons' desires, and that may conceivably be the reason why being engaged in (or attached to) the activities never contributed to making the persons' lives meaningful (whatever they themselves used to believe about it). No particular value requirement on meaning in life is needed for that explanation. It should furthermore be noticed that it is surely conceivable also that some people live for the projects that they do without any particular concern for whether the relevant projects are objectively valuable or not (my guess would be that this is actually true for quite a few people): the projects matter to them, and that is all there is to it. And with respect to such people, hybrid theories - or subjectivist theories with a value requirement - seem unavoidably elitist.

\section{Subjectivism II: Subjectivist Theories Without a Value Requirement}

Let us now move on to consider instead subjectivist theories without any value requirement. ${ }^{26}$ Below I will first distinguish between two kinds of subjectivist theory:

26 Such theories are strikingly unfashionable among philosophers working on meaning in life today (for a few exceptions, see Harry Frankfurt, 'The Importance of What We Care About', in The Importance of What We Care About (Cambridge: Cambridge University Press, 1998), and The Reasons 
state-of-mind vs. state-of-the-world theories (4.1). ${ }^{27} \mathrm{I}$ will then show why state-of-mind theories of what makes a person's life meaningful should be rejected (4.2). This leaves us with state-of-the-world theories, and I will argue that the most promising version of such a theory is CDF (4.3).

\subsection{Two Kinds of Subjectivist Theory}

We may recall that according to subjectivism, the meaning in your life depends (at least partly) on 'your set of attitudes or concerns'. ${ }^{28}$ Now, on one kind of subjectivist theory the meaning in your life depends entirely on your mental states, whereas on another kind of subjectivist theory it also depends on states of the world (on states outside of your mind). According to the former kind, whether a person's life is meaningful is determined solely by the extent to which s/he favours - in the sense of likes, enjoys, finds pleasant or fulfilling-what is the case and what happens. According to the latter kind, whether one's life is meaningful is instead determined by the extent to which one's desires are satisfied or fulfilled. And since many of our desires are indeed about the state of the world - that we actually do, achieve, or have this or that - meaning in life is, on this second kind of theory, dependent on the state of the world as well as on our attitudes.

\subsection{Against Mental-State Theories}

Could the meaning in our lives plausibly depend only on the quality of our mental states - on the extent to which we, e.g., like, enjoy, or take pleasure in our circumstances? With respect to most of us, at least, it seems that the answer to that question must clearly be no. The reason for this is that if meaning did depend only on the quality of our mental states, then it would not really matter whether the circumstances that we favour (like, enjoy, take pleasure in) correspond to the circumstances that we are actually in. But to most of us that makes a crucial difference! For example, suppose that I for many years have found great fulfillment and pleasure in my marriage, my friendships, my work, and in my personal projects. Then one day it is suddenly revealed to me that, just as in the movie The Truman Show, my life has in fact been rigged since day one and broadcasted around the world by a sinister media production company. All of the things that I have found so rewarding and cared so deeply about were actually fake: my 'wife', my 'colleagues', my 'friends' - they were all just actors following a script in their relations to me. Now was my life nevertheless meaningful up to the point when it was revealed to me what was really going on? Obviously not, I would say. What I cared about, and desired to continue, was being in a loving relationship, having close friends, an interesting job, and so on, none of which actually obtained in my life. Contrary to what I

of Love (Princeton: Princeton University Press, 2004); Steven Luper, 'Life's Meaning', in The Cambridge Companion to Life and Death, edited by Steven Luper (Cambridge: Cambridge University Press, 2014); Richard Taylor, Good and Evil: A New Direction (New York: Macmillan, 1970), chapter 18; and Williams, 'Persons, Character and Morality'), something which is, I suspect, to a large extent due to some of the objections that we will consider in section 5 .

27 Subjectivist theories with a value requirement (Wolf's theory, e.g.), belong to the second of these two kinds. However, since the hybrid theory was rejected in the previous section, I will set it to one side in the present section. It is noteworthy, I think, that the distinction between two kinds of subjectivist theory has been generally neglected so far in the meaning in life literature.

28 Sumer, Welfare, Happiness, and Ethics, p. 81. 
believed before the discovery, there was no basis within my life 'for the needs or longings that are characteristically described as needs for meaning' ${ }^{29}$

Now, I have been talking about myself here. And even though I feel confident that what I have said holds for many other people as well, I see no reason to completely rule out the possibility that there could be persons who really do care only about what they feel or experience (about the quality of their own mental states), and not at all about the state of the world, and with respect to whose lives it could indeed correctly be said that in the Truman Show scenario, their lives were indeed meaningful at least up to the point when the truth about their circumstances was revealed to them. However, the meaningfulness in their lives would plausibly result from the satisfaction of their desires for having certain experiences, and not from the experiences themselves.

\subsection{Desire-Based Subjectivism}

Mental-state theories, as we just saw, put too much emphasis on ... well, on people's mental states. A plausible theory of what makes a person's life meaningful should be able to accommodate the fact that many of us care deeply about different facets of the state of the world-about what is actually the case and what actually happens-and not (or at least not just) about how we feel. What we may call desire-based theories can indeed accommodate this fact.

According to desire-based theories, what makes one's life meaningful is a matter of the extent to which one's desires are satisfied or fulfilled. Desire-based theories are thus clearly subjectivist, since they entail that meaning in life is dependent on one's 'set of attitudes and concerns'; more specifically on one's desires. But since our desires often concern some aspect of the state of the world, desire-based theories also entail that meaning in life depends on the extent to which the world actually corresponds to, or fits with, our desires.

I believe that the correct theory of what makes a person's life meaningful (if there is indeed a correct theory to be found about this) must be of the desire-based kind. However, it does not seem very plausible to settle simply for an unqualified or straightforward desire-satisfactionism, according to which the satisfaction of just any desire that a person may have confers (at least some amount of) meaning on that person's life. There are at least two reasons for why such a view would be implausible. To begin with, some of our desires are without any deeper significance or importance to us. They may be desires for things that we enjoy and/or find relaxing, but which do not mean anything to us on a deeper level of our lives. Wielenberg, e.g., suggests that for him the desire to play video games is of this kind, and Wolf can perhaps be read as at least hinting that solving sudokus play such a role in her life..$^{30}$ For my own part, I could mention desires for reading gangster novels, having a cold beer on warm summer afternoons, and perhaps watching episodes of Family Guy. While I certainly enjoy these things, and often desire to do them, they are not part of what makes the world go round

29 Wolf, 'Happiness and Meaning: Two Aspects of the Good Life', p. 109.

30 See Wielenberg, Value and Virtue in a Godless Universe, p. 34f; and Wolf, Meaning in Life and Why It Matters, p. 16. 
for me; it would not affect my judgment about whether my life is worthwhile if I had to give them up or became unable to satisfy them anymore. ${ }^{31}$

It is perhaps worth stressing that my claim above is not that the satisfaction of the relevant kind of desires fails to confer meaning on one's life because they are desires for objectively worthless or unimportant things. My claim is rather there is a dimension of depth to meaning in life that the satisfaction of the relevant kind of desires fails to meet. However, the satisfaction of which desires that indeed have the required dimension of depth is determined subjectively: reading gangster novels, playing video games, or solving crossword puzzles, may indeed be of deep significance in the lives of some people, and for them the satisfaction of their desires for those things would plausibly confer some amount of meaning on their lives.

It is perhaps also worth pointing out that I am not claiming that the satisfaction of the kind of desires that are at issue here is necessarily inconsequential for our overall wellbeing. As suggested in section 1 (remark (iv)), I think meaning in life constitutes one aspect of wellbeing. But there may very well be-and quite plausibly are-other aspects of wellbeing as well, including, e.g., the pleasure we usually receive from fulfilling the kind of desires that I have been talking about above.

The second reason for why unqualified or straightforward desire-satisfactionism would be implausible as a theory of what makes for a meaningful life, is that some of our desires are ones that we wish or desire that we did not have. They are such that we feel alienated from them; they are, in an important sense, not our own. But the satisfaction of desires that are not really our own cannot plausibly contribute to making our lives meaningful.

\subsubsection{A Better Alternative}

But what might then constitute a better or more satisfactory desire-based account than unqualified desire-satisfactionism? In answer to this question, I propose CDF, i.e. the view that whether your life is meaningful depends on the extent to which your categorical desires-those desires that are in part constitutive of your practical identity-are fulfilled. CDF avoids both of the problems for unqualified desire-satisfactionism that were mentioned above. On the one hand, the desires the fulfilment of which contributes to making one's life meaningful, according to $\mathrm{CDF}$, are ones that run quite deep in oneself; indeed, they must be partly constitutive of who one is as a particular practical agent. On the other hand, precisely because the relevant desires must be constitutive components of one's practical identity, the satisfaction of uncharacteristic or alien desires cannot, on CDF, confer meaning on one's life. ${ }^{32}$

\footnotetext{
31 If someone prevented me by force from satisfying these desires, then that could very well affect my judgment about the worthwhileness of my life. But that would affect my judgment because it would constitute a violation of my integrity, not because I was no longer able to satisfy my desires for the relevant things.

32 Alien desires are not ones that we identify with; they would not figure 'in a description under which ... you find your life to be worth living and your actions to be worth undertaking' (Korsgaard, The Sources of Normativity, p. 101). And therefore they are not constitutive of your practical identity or normative self-conception.
} 
Much more could of course be said regarding the details of CDF. However, I hope to have said enough to at least convince you that CDF deserves our serious attention. I will therefore turn next to considering a number of objections that could conceivably be raised against it.

\section{Objections and Responses}

In this section I will raise and offer responses to at least four different objections against CDF. ${ }^{33}$ In brief, the objections to be discussed are the following:

(5.1) CDF has radically counterintuitive implications regarding which lives that qualify as meaningful!

(5.2) CDF cannot properly account for the importance of experiencing a sense of fulfillment in living a meaningful life!

(5.3) CDF has radically counterintuitive implications regarding which lives that count as more or less meaningful!

(5.4) CDF cannot make sense of the possibility of epiphanies, in the light of which people come to realize that, contrary to what they used to believe, their lives to date have in fact been wasted or meaningless!

\subsection{Counterintuitive Implications I}

By far the most common objection to subjectivist theories without a value requirement in the recent literature is that they have 'seriously counterintuitive implications about which lives count as meaningful' ${ }^{34}$ If the satisfaction or fulfillment of desires, e.g., was all that meaning in life depended on, then it seems we could acquire meaning in our lives even from such activities as (just to mention a few of the many examples available in the literature): spending 'day after day, or night after night, in front of a television set, drinking beer and watching situation comedies'35; 'collecting rubber band'36; 'memorizing the dictionary'37; 'making handwritten copies of war and peace'38; 'counting the blades of grass on Harvard Yard'39; 'collecting bottle tops'40; and 'smoking pot all day'. ${ }^{41}$ But it is radically (or 'seriously') counterintuitive, we are invited to agree, that activities such as

33 As will become apparent, the objections are such that they concern desire-based (and in some cases maybe subjectivist) theories in general. In my responses to them, though, I will focus specifically on how they can be handled by CDF.

34 Metz, Meaning in Life, p. 175.

35 Susan Wolf, 'The Meanings of Lives', in The Variety of Value: Essays on Morality, Meaning, and Love (Oxford: Oxford University Press, 2015), p. 92.

36 Wolf, 'Happiness and Meaning: Two Aspects of the Good Life', p. 112.

37 Ibid.

38 Ibid.

39 Smuts, 'The Good Cause Account of the Meaning of Life', p. 536.

40 Singer, Meaning of Life, p. 113.

${ }^{41}$ Wolf, Meaning in Life and Why It Matters, p. 9. All these examples could be used also as objections against the kind of subjectivist view according to which meaning in life depends entirely on the extent to which one likes, enjoys, or takes pleasure in one's circumstances. 
these could contribute to making anyone's life meaningful. And so subjectivist theories without a value requirement, including $\mathrm{CDF}$, have to go.

\subsubsection{Response(s).}

In response to this objection, we might begin by pointing out that, according to CDF at least, the examples listed just above do not qualify as putative counterexamples unless it is assumed that a person's desire for either of the relevant activities is neither alien nor too shallow or unimportant to her, but rather constitutes a categorical desire-a desire that is partly constitutive of her practical identity. And once this point has been made clear, I must admit that I simply do not find it counterintuitive to think that the activities in question could conceivably contribute to making certain people's lives meaningful. If one or more of the relevant activities really are objects of someone's categorical desires - if they are objects of desires such that the person would find that his or her life had diminished seriously in its worthwhileness if $s /$ he were to lose them or had to give them up - then why would not their satisfaction be said to contribute to making the person's life meaningful? Indeed, in line with my critique earlier of hybrid theories (section 3), I do not quite see how it could be anything but unacceptably elitist to deny that it would.

What I have just said is of course compatible with there being many other things that we might reasonably want to point out to someone (if, that is, we ever were to meet such a person, which we quite probably will not) who really does seem to acquire some amount of meaning in his life from one or more of the activities in the examples above. Out of concern for that person's own interest, we could point out, e.g., that drinking beer night after night in front of the TV, or smoking pot all day, will harm both his physical health and his intellectual abilities (which the person may certainly also care about!). The person should also consider the social costs associated with the relevant activities: for example, it will quite likely be very hard to initiate and sustain friendly and loving relationships to others if one spends every night drinking beer in front of the TV and/or smoking pot all day. Furthermore, as with most activities - whether they belong to those that philosophers like to suggest are objectively valuable or not - if we engage in them too much too often, we will grow tired of them. And so if someone spends all of his waking hours making handwritten copies of War and Peace, we might quite reasonably point out that he should consider what he will do when that activity loses its grip on him. ${ }^{42}$

\subsection{Meaning and the Importance of Feeling Fulfilled}

In 4.2 I argued that the meaning in most people's lives plausibly depends not just on how they feel towards their circumstances but also on the state of the world, and that mentalstate theories of meaning in life should therefore be rejected. Perhaps, however, it will be objected that by endorsing CDF I have instead gone too far in the opposite direction. Could it not be the case, after all, that the world actually fits with many of a person's desires - even with her categorical ones - even though the person does not enjoy, finds pleasure in, or feels fulfilled by her circumstances (perhaps because she is unaware of the

42 In addition to these kinds of prudential considerations, it seems we could very plausibly also point to various moral considerations that the person is ignoring while being engaged in at least some of the relevant activities. 
extent to which her categorical desires are fulfilled)? And if this is indeed the case-i.e. if CDF turns out to entail that liking, enjoying, or feeling fulfilled by one's circumstances, is not even a necessary condition for exemplifying meaning in one's life - then that, the critic might suggest, constitutes a serious blow against CDF.

\subsubsection{Response(s).}

It seems to me quite correct that CDF denies the necessity of liking, enjoying, or feeling fulfilled by one's circumstances in order for a person's life to exemplify meaning. But this does not constitute a problem for CDF, I think; it is rather just as it should be.

It may be worth stressing that what is at issue here is not whether a person's categorical desires must, to some extent or other, be satisfied in order for that person's life to exemplify meaning. What is at issue is instead if the satisfaction of a person's categorical desires is, as CDF claims, both necessary and sufficient in order for a person's life to exemplify meaning, or if it is also required that the person feels in a certain way towards her circumstances - if she in addition must take pleasure in or feel fulfilled by them. Of course, these things often go hand in hand: we are often aware of when our desires are satisfied, and, at least in the normal case, I take it we also experience a sense or feeling of satisfaction or fulfillment when they are. But it seems some of our desires and why not our categorical ones? - sometimes can really be satisfied without our knowledge of it; we may even firmly believe that they are in fact not satisfied. In such cases - and I will offer an illustration of one in a minute-something that one cares about deeply (assuming at least that we are thinking of a case involving a categorical desire) would in fact be fulfilled. Now, is it not, upon reflection, quite plausible to think that that would indeed contribute to making one's life more meaningful? It seems it would provide some basis within one's life for an affirmative answer to questions about whether one's life has (or have had) a point or purpose, even though one would not happen to have cognitive access to that basis in the relevant kind of case.

For illustration, let us consider an example provided by Aaron Smuts. Smuts brings to our attention the case of George Baily, the main character in the classic movie It's A Wonderful Life:

The movie tells what is now a familiar story of a suicidal man, George Baily (James Stewart), who is finally able [to] see the meaning of his life with a little help from a friend-an alcoholic angel who wants to make good. The angel takes George on a trip to Pottersville - the alternate world where George had never been born. A few hours in Pottersville is enough for George to see how meaningful his existence has been. 43

I believe Smuts is right that the case of Baily should help us see 'that one can live a meaningful life, but mistakenly think otherwise' - without, as I would put it, having favourable feelings towards what one takes to be one's circumstances. ${ }^{44}$ Indeed, even if Baily 'had not been shaken out of his mistaken evaluation ... [his] life would still have

${ }^{43}$ Smuts, 'The Good Cause Account of the Meaning of Life', p. 544.

44 Ibid., p. 547. 
been meaningful. He would not have realized it. In fact, he probably would have killed himself ... But this would not make his life meaningless'. ${ }^{45}$

However, I part company with Smuts when it comes to the explanation for why Baily's life plausibly exemplifies meaning even before he is taken to Pottersville (and of why his life would have done so even if he had never been taken to Pottersville at all). What makes that plausible, in my view, is that Baily really cares about the welfare of the people around him - that he has what certainly seems to be a categorical desire for doing what he can to promote their good - and that he, contrary to what he thinks before the trip to Pottersville, in fact does (and has done) just that. On Smuts' consequentialist view, on the other hand, the good that Baily causes is all that matters. But this means that Baily's life would have exemplified meaning even if his trip to Pottersville had only confirmed his belief that the world does not conform to his desires or concerns (which, in this scenario, would not include doing what he can to promote the good of those around him). And that seems to me unacceptable since there would then be no connection or link between what makes Baily's life meaningful, and his set of attitudes or concerns.

\subsection{Counterintuitive Implications II}

According to Smuts, it 'is a core datum that any theory of meaning of life must respect on pain of radical revisionism' that 'Gandhi's life is more meaningful than one spent making handwritten copies of War and Peace, collecting rubber bands, counting the blades of grass on Harvard Yard, or consuming large quantities of excrement'. ${ }^{46}$ And a bit further on in his paper, Smuts argues that subjectivism (without a value requirement) fails to respect to this 'core datum', since according to it:

any two equally fulfilling lives are equally meaningful, even if one is devoted to curing cancer and the other to consuming vast quantities of excrement. But a grinning excrement eater does not live as meaningful of a life as a cancer researcher. It is absurd to suggest otherwise. Hence, we should reject the subjective theory. ${ }^{47}$

Throughout his paper, Smuts seems to identify subjectivism (or 'the subjective theory') with the view 'that what makes a life meaningful is purely a matter of how that life seems to the one who lives it'. ${ }^{48}$ As we have seen, though, this is not an accurate characterization with respect to the desire-based kind of subjectivist theory. However, it seems Smuts' argument above could easily be amended to cover the desire-based kind of subjectivist theory as well. We could just rephrase the beginning of the argument so that it reads instead: 'any two equally fulfilling lives - or, for the desire-based kind of theory, any two lives in which the persons' desires are satisfied to an equal degree-are equally meaningful ...'.

45 Ibid., p. $546 f$.

46 Ibid., p. 536.

47 Ibid., p. $543 f$.

48 Ibid., p. 541. 


\subsubsection{Response(s).}

The first thing we may notice is that this is a somewhat surprising argument coming from a consequentialist such as Smuts. It is surely possible, after all, to think of circumstances (highly improbable though they may be) in which a life 'spent making handwritten copies of War and Peace, collecting rubber bands, counting the blades of grass on Harvard Yard, or consuming large quantities of excrement' would be the cause of as much (and maybe even more) good as (than) Gandhi's life was. And on Smuts' own favoured theory-GCA (discussed in 2.1 above) - the former life would in such circumstances also count as equally (more) meaningful as (than) Gandhi's. Indeed, it seems we could easily turn his argument against subjectivism into one directed at GCA instead: any two equally [good producing] lives are equally meaningful, even if one is devoted to curing cancer and the other to consuming vast quantities of excrement. But a grinning excrement eater does not live as meaningful of a life as a cancer researcher. It is absurd to suggest otherwise. Hence, we should reject [GCA].

Perhaps it will be responded that what Smuts means must reasonably be that what is absurd about subjectivism is that it entails that any two lives that are equally fulfilling - or equal in respect of desire satisfaction - are thereby equally meaningful, 'even if one is devoted to curing cancer and the other to consuming vast quantities of excrement'. The problem with this response, though, is that the reason Smuts offers for why this is absurd is that 'a grinning excrement eater does not live as meaningful of a life as a cancer researcher'. But that, as we have seen, is not a claim that GCA respects in all conceivable circumstances either.

Whether or not Smuts' argument hits his own favoured theory, however, the question of what can be said in defense of CDF in relation to the relevant argument still remains. I shall thus turn to that question now.

Let us begin by setting Smuts' quite extreme examples to one side for a moment, and consider instead a comparison between, say, Gandhi's life, on the one hand, and the life of a Western middle class academic, whose life revolves primarily around her family, her job as a university physics professor, travelling, music, and gliding, on the other. Now, is there any reason to think that the second life must have within it a weaker basis for affirmative answers to questions about whether there is a point, purpose or direction to it, than what the first life has? Of course, the first life - it is Gandhi's life, after all! - will in all likelihood be the cause of a much greater amount of good in the world at large (that will presumably be the case in comparison to the lives of the vast majority of people in the world). But let us suppose that while the person living the second life is indeed concerned to be a morally upright person, and also greatly admires Gandhi, wishing that there were more persons like him in the world, she does not cherish any categorical desires for achievements or accomplishments similar to Gandhi's, but rather for precisely the things around which her life presently revolves. For my own part, at least, I fail entirely to see why the second life, under these circumstances, could not be just as meaningful as the first life.

But it may now be asked whether the same could really be said for a life devoted to making handwritten copies of War and Peace, collecting rubber bands, and so on? I believe it reasonably could, at least as long as we keep in mind some of the things said in response to the first objection earlier (5.1) - in particular that we must make sure that we are conceiving of the relevant life as one in which making handwritten copies of War and 
Peace and/or collecting rubber bands really are the objects of someone's categorical desires. That is perhaps not so easy to do since it is so unlikely that we have ever met, or ever will meet, a person for whom this is indeed the case. But it is not, it seems to me, impossible to conceive of such a person. And once we do, I do not see why we would - or should - deny that that person exemplifies (some amount of) meaning in his or her life.

\subsection{Wolf's Objection}

Susan Wolf has argued that subjectivism without a value requirement obliterates the difference between one's life merely feeling or seeming meaningful to one, and one's life actually being meaningful. But this difference is crucial, according to Wolf, in order for us to make sense of the possibility of waking up 'either literally or figuratively - to the recognition that one's life to date has been meaningless'. ${ }^{49}$

\subsubsection{Response(s).}

On one natural way of understanding this objection, it is at most an objection against mental-state theories of meaning in life-i.e. against theories according to which the meaning of one's life depends entirely on what one experiences one's life to be like. The desire-based kind of subjectivist theories (including CDF) instead make the meaningfulness of one's life depend at least in part on the state of the world, and about that we can of course be mistaken. A desire-based theory such as CDF therefore also does leave room for the possibility of discovering that one's life to date has in fact been meaningless, contrary perhaps to what one used to think; this was indeed the point of the Truman Show example in 4.2.

But maybe it will be responded here that even if CDF leaves room for the possibility of making one kind of mistake regarding the meaningfulness in one's life to date, there is a second kind of mistake that one could make about that, which CDF does not leave room for. The second kind of mistake shows up in cases where we have been attached to activities on the assumption that the relevant activities are objectively valuable. When realizing that those activities were not, in fact, objectively valuable, however, we are forced to acknowledge that our lives to date have been meaningless.

It is not true, however, that CDF rules out even this second kind of mistake. Insofar as one has been attached to activities that one desired on the condition that they were objectively valuable, then the realization that the relevant things were actually not objectively valuable would indeed entail, even according to CDF, that one's life to date has been meaningless (this was indeed one of the points made in section 3 earlier).

\section{Summary}

In this paper I have proposed and defended a particular desire-based theory of what makes a person's life meaningful. Desire-based theories, I have argued, avoid the problems facing other theories of meaning in life: in contrast to objectivist theories (both consequentialist and non-consequentialist ones), they succeed in providing a necessary link between what makes a person's life meaningful and the person's own set of attitudes

${ }^{49}$ Wolf, 'The Meanings of Lives', p. 96. 
or concerns; in contrast to hybrid theories (or subjectivist theories with a value requirement), they avoid the elitism or exclusivism inherent in the former; and in contrast to mental-state theories, they avoid the problem of not taking the state of the world properly into account when determining whether someone's life is meaningful. However, since the meaning in one's life does not plausibly depend on the satisfaction of just any desires - perhaps especially not on the satisfaction of desires that we experience as alien to ourselves - I suggested that we should opt for CDF, i.e. the view that the meaning in your life depends on the extent to which your categorical desires are satisfied or fulfilled. Lastly, I raised and responded to at least four possible objections to CDF.

While CDF seems to me the most plausible theory available so far, a lot certainly remains to be done with respect to working out all the details and implications of it. Furthermore, it is still early days in analytically oriented philosophy for the topic of meaning in life. Much work still needs to be done regarding, e.g., the concept-or concepts - of meaning in life; the value of living a meaningful life; and the development and critical examination of new substantive conceptions of it. That work will of course also be relevant for evaluating CDF. However, I hope to at least have made a case for taking CDF-as well, perhaps, as desire-based theories more generally-seriously in future philosophical discussions. ${ }^{50}$

Frans Svensson, Umeå University frans.svensson@umu.se

\section{Bibliography}

Annas, Julia. Intelligent Virtue. Oxford: Oxford University Press, 2011.

Aristotle. Nicomachean Ethics, translated and edited by Roger Crisp. Cambridge: Cambridge University Press, 2000.

Audi, Robert. 'Intrinsic Value and Meaningful Life', Philosophical Papers 34:3 (2005), pp.331-355.

Bramble, Ben. 'Consequentialism about Meaning in Life', Utilitas 27:4 (2015), pp. 445-459.

Broogard, Berit, and Smith, Barry. 'On Luck, Responsibility and the Meaning of Life', Philosophical Papers 34:3 (2005), pp. 443-458.

Darwall, Stephen. Welfare and Rational Care. Princeton: Princeton University Press, 2002.

Evers, Daan, and van Smeden, G.E. 'Meaning in Life: In Defense of the Hybrid View', Southern Journal of Philosophy 54:3 (2016), pp. 355-371.

Flanagan, Owen. Self-Expressions: Mind, Morals, and the Meaning of Life. Oxford: Oxford University Press, 1996.

Foot, Philippa. Natural Goodness. Oxford: Oxford University Press, 2001.

Frankfurt, Harry. 'The Importance of What We Care About', in The Importance of What We Care About. Cambridge: Cambridge University Press, 1988.

\footnotetext{
50 I am very grateful to all who contributed to the discussions of earlier (and in some respects quite different) versions of this paper at the universities of Nottingham, Oslo, Stockholm, Uppsala, and Umeå. In particular I wish to thank Per Algander, Daan Evers, Madeleine Hayenhjelm, Andreas Hjälmarö, Jens Johansson, Thaddeus Metz, Susan Wolf, and Chris Woodard. I also received helpful comments from two anonymous reviewers.
} 
De Ethica. A Journal of Philosophical, Theological and Applied Ethics Vol. 4:3 (2017)

Frankfurt, Harry. The Reasons of Love. Princeton: Princeton University Press, 2004.

Hepburn, R.W. 'Questions about The Meaning of Life', Religious Studies 1:2 (1966), pp. 125-140.

Kahane, Guy. ‘Our Cosmic Insignificance', Nous 48:4 (2014), pp. 745-772.

Kauppinen, Antti. 'Meaningfulness and Time', Philosophy and Phenomenological Research 84:2 (2012), pp. 345-377.

Korsgaard, Christine M. The Sources of Normativity. Cambridge: Cambridge University Press, 1996.

Kraut, Richard. 'Two Conceptions of Happiness', The Philosophical Review 88:2 (1979), pp. 167- 197.

Luper, Steven. 'Life's Meaning', in The Cambridge Companion to Life and Death, edited by Steven Luper. Cambridge: Cambridge University Press, 2014.

Markus, Arjan. 'Assessing Views of Life: A Subjective Affair?', Religious Studies 39:2 (2003), pp. 125-143.

May, Todd. A Significant Life: Meaning in a Silent Universe. Chicago: University of Chicago Press, 2015.

Metz, Thaddeus. Meaning in Life: An Analytic Study. Oxford: Oxford University Press, 2013.

Nagel, Thomas. 'Secular Philosophy and the Religious Temperament', in Secular Philosophy and the Religious Temperament: Essays 2002-2008. Oxford: Oxford University Press, 2010.

Russell, Daniel C. Happiness for Humans. Oxford: Oxford University Press, 2012.

Smuts, Aaron. 'The Good Cause Account of the Meaning of Life', The Southern Journal of Philosophy Volume 51: 4 (2013), pp. 536-562.

Singer, Irving. Meaning of Life, Vol. 1: The Creation of Value. Baltimore: John Hopkins University Press, 1996.

Sumner, L. Wayne. Welfare, Happiness, and Ethics. Oxford: Oxford University Press, 1996.

Taylor, Richard. Good and Evil. New York: Macmillan, 1970.

Wells, Mark. 'Meaning in Consequences', Journal of Philosophy of Life 5:3 (2015), pp. 169179.

Wielenberg, Erik J. Value and Virtue in a Godless Universe, Cambridge: Cambridge University Press, 2005.

Williams, Bernard. 'Persons, Character and Morality', in Moral Luck: Philosophical Papers 1973-1980. Cambridge: Cambridge University Press, 1981.

Williams, Bernard. 'The Makropulos Case; Reflections on the Tedium of Immortality', in Problems of the Self: Philosophical Papers 1956-1972. Cambridge: Cambridge University Press, 1973.

Wolf, Susan. 'The Meanings of Lives', in The Variety of Values: Essays on Morality, Meaning, and Love. Oxford: Oxford University Press, 2015.

Wolf, Susan. 'Happiness and Meaning: Two Aspects of the Good Life', in The Variety of Values:

Essays on Morality, Meaning, and Love. Oxford: Oxford University Press, 2015.

Wolf, Susan. Meaning in Life and Why It Matters. Princeton: Princeton University Press, 2010.

Woodard, Chris. 'What Good is Meaning in Life?', De Ethica, this issue. 